\title{
Dextran from Leuconostoc mesenteroides-doped ammonium salt-based green polymer electrolyte
}

\author{
M H HAMSAN ${ }^{1}$, M F SHUKUR ${ }^{2}, S$ B AZIZ ${ }^{3,4}$ and M F Z KADIR ${ }^{5, * 10}$ \\ ${ }^{1}$ Institute of Graduate Studies, University of Malaya, Kuala Lumpur 50603, Malaysia \\ ${ }^{2}$ Fundamental and Applied Sciences Department, Universiti Teknologi PETRONAS, Seri Iskandar 32610, Perak, Malaysia \\ ${ }^{3}$ Advanced Polymeric Materials Research Lab, Department of Physics, College of Science, University of Sulaimani, \\ Sulaimani 46001, Iraq \\ ${ }^{4}$ Komar Research Center (KRC), Komar University of Science and Technology, Sulaimani 46001, Iraq \\ ${ }^{5}$ Centre for Foundation Studies in Science, University of Malaya, Kuala Lumpur 50603, Malaysia \\ *Author for correspondence (mfzkadir@um.edu.my)
}

MS received 29 March 2018; accepted 7 August 2018; published online 6 March 2019

\begin{abstract}
Biopolymer electrolytes based on dextran from Leuconostoc mesenteroides doped with ammonium nitrate $\left(\mathrm{NH}_{4} \mathrm{NO}_{3}\right)$ are synthesized via a solution cast method. Fourier transform infrared analysis is used to determine the complexation between cation from the salt with functional groups of dextran. The ionic conductivity of undoped dextran film at room temperature is identified as $(8.24 \pm 0.31) \times 10^{-11} \mathrm{~S} \mathrm{~cm}^{-1}$. A conductivity of $(3.00 \pm 1.60) \times 10^{-5} \mathrm{~S} \mathrm{~cm}^{-1}$ is achieved with the inclusion of $20 \mathrm{wt} \% \mathrm{NH}_{4} \mathrm{NO}_{3}$ to the pure dextran film. The conductivity at a high temperature of the electrolyte obeys Arrhenius theory. Field emission scanning electron microscopy results show that the highest conducting sample has a porous surface. Results from the dielectric study show a non-Debye characteristic.
\end{abstract}

Keywords. Biopolymer; dextran; ammonium nitrate; dielectric; ionic conductivity.

\section{Introduction}

Biomaterials and natural products are good candidates to be used in research activities due to awareness of global crisis. Many researchers have incorporated biopolymers as the polymer host in electrolytes due to its magnificent characteristics, such as easy film formation and compatibility with a wide range of salts and solvents [1]. Furthermore, most biopolymers can be sustainably acquired from a large range of natural resources. Above all natural polymeric materials are eco-friendly and thus their use for electrolyte applications reduces harm towards human health and environment $[2,3]$.

Biopolymers are extracted from a wide range of resources such as cellulose derivatives, chitosan, carrageenan, pectin, starch and lignin [4-10]. These polymers possess a lone pair electron of the heteroatom such as nitrogen or oxygen and hence ionic dopant can be solvated [11]. Dextran is one of the non-toxic and biodegradable polysaccharides obtained from reproduction of bacteria Leuconostoc mesenteroides. Dextran possesses a linear polymer backbone with primary linkages of $1,6-\alpha$-D-glucopyranosidic [12]. Typically, dextran is used in the medical field as a drug carrier, substitute of blood, in bone curing and plasma modification. In the structure of dextran, the presence of hydroxyl group ensures the polymer to be used as an ionic conductor [13].

There are various types of salt that have been used as ionic dopants e.g., lithium, sodium, silver and ammonium salt.
However, some alkali metal salts such as lithium and sodium salts have disadvantages such as reactive with $\mathrm{H}_{2} \mathrm{O}$ and thermally unstable [14]. In addition, polymers in lithium-based polymer electrolytes require rich electron functional groups for the conduction of $\mathrm{Li}^{+}$ions [15]. The solvent for inorganic salts such as sodium iodide and potassium iodide are limited [16]. Ammonium salts show a high conductivity value. The use of ammonium salt is also helpful to avoid the use of expensive lithium metal as an electrode in battery applications [17]. In this work, dextran and ammonium nitrate $\left(\mathrm{NH}_{4} \mathrm{NO}_{3}\right)$ have been used as a polymer host and an ion source, respectively.

\section{Methods and procedures}

\subsection{Preparation of samples}

Dextran powder ( $2 \mathrm{~g}$ ) (Sigma-Aldrich) was poured in $50 \mathrm{ml}$ of $1 \%$ acetic acid at room temperature for $40 \mathrm{~min}$. After the dextran was completely dissolved, different concentrations of $\mathrm{NH}_{4} \mathrm{NO}_{3}$ (SYSTERM) were included in the solution of dextran. The solution was poured into Petri dish. The sample was left to dry at room temperature. The formed films were then placed in a desiccator. The compositions for the electrolytes are shown in table 1. 
Table 1. Designation for the electrolytes.

Dextran: $\mathrm{NH}_{4} \mathrm{NO}_{3}$

composition (wt\%)

Designation

\begin{tabular}{lc}
\hline $100: 0$ & S0 \\
$95: 5$ & S5 \\
$90: 10$ & S10 \\
$85: 15$ & $\mathrm{~S} 15$ \\
$80: 20$ & $\mathrm{~S} 20$ \\
$75: 25$ & $\mathrm{~S} 25$ \\
$70: 30$ & $\mathrm{~S} 30$ \\
\hline
\end{tabular}

\subsection{Sample characterization}

Spotlight 400 Perkin-Elmer spectrometer was used to conduct Fourier transform infrared (FTIR) spectroscopy with a resolution of $1 \mathrm{~cm}^{-1}\left(450-4000 \mathrm{~cm}^{-1}\right)$. The surface of the electrolyte was observed via Hitachi SU8220 field emission scanning electron microscopy (FESEM) with $10 \mathrm{k} \times$ magnification. X-ray diffraction (XRD) analysis was conducted via a D5000 X-ray diffractometer (1.5406 $\AA$ ). The $2 \theta$ angle was varied from 5 to $80^{\circ}$ (resolution $=0.1^{\circ}$ ). HIOKI 353250 LCR HiTESTER was employed to analyse electrical impedance spectroscopy measurements of the samples $(50 \mathrm{~Hz}$ to $5 \mathrm{MHz}$ ). The sample was placed in between two electrodes (stainless steel) of a conductivity case. The bulk resistance $(R)$ of the sample was gained from the Cole-Cole plots. The conductivity value was obtained from:

$$
\sigma=\frac{x}{R A_{\mathrm{s}}}
$$

where $A_{\mathrm{s}}$ stands for contact area between electrode and electrolyte and the thickness is given as $x$.

\section{Results}

\subsection{FTIR analysis}

Figure 1a depicts the spectra of dextran- $\mathrm{NH}_{4} \mathrm{NO}_{3}$ complexes for the region of hydroxyl band. The dextran's hydroxyl peak is centred at $3310 \mathrm{~cm}^{-1}$ which is similar to the work reported by other studies $[12,18]$. The hydroxyl band in dextran experienced some shift on the inclusion of $20 \mathrm{wt} \% \mathrm{NH}_{4} \mathrm{NO}_{3}$ from 3310 to $3245 \mathrm{~cm}^{-1}$. This phenomenon portrays the dative bond interaction between cations with the oxygen atoms of dextran [19]. Two peaks appear when more than $20 \mathrm{wt} \%$ $\mathrm{NH}_{4} \mathrm{NO}_{3}$ is doped to the polymer matrix. These two peaks represent the asymmetry $\left(v_{\text {as }}\left(\mathrm{NH}_{4}^{+}\right)\right)$and symmetry vibration $\left(v_{\mathrm{s}}\left(\mathrm{NH}_{4}^{+}\right)\right)$of $\mathrm{NH}_{4}^{+}$which are positioned at 3224 and $3060 \mathrm{~cm}^{-1}$, respectively, in the spectrum of $\mathrm{NH}_{4} \mathrm{NO}_{3}$. Kadir et al [20] stated that in the spectrum of chitosan- $\mathrm{NH}_{4} \mathrm{NO}_{3}$

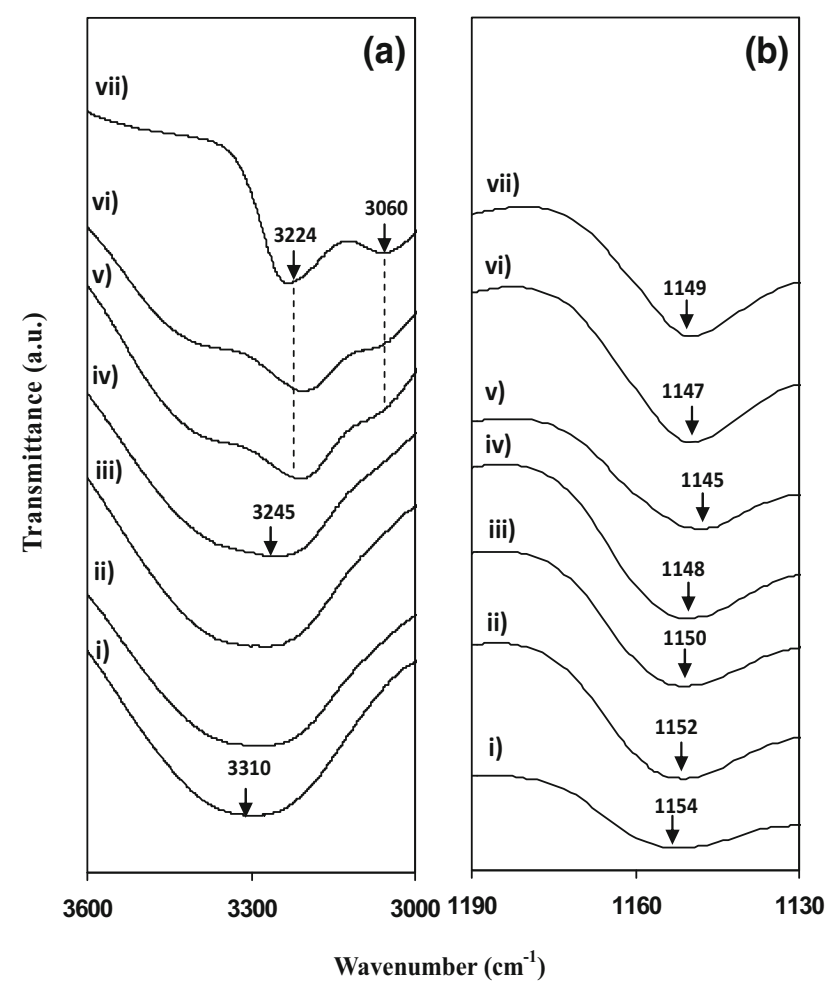

Figure 1. (a) FTIR spectra for (i) pure dextran (S0), (ii) $\mathrm{S} 5$, (iii) $\mathrm{S} 15$, (iv) $\mathrm{S} 20$, (v) $\mathrm{S} 25$, (vi) $\mathrm{S} 30$ and (vii) $\mathrm{NH}_{4} \mathrm{NO}_{3}$ in the 3000-3600 $\mathrm{cm}^{-1}$ spectra region. (b) FTIR spectra for (i) pure dextran (S0), (ii) S5, (iii) S10, (iv) S15, (v) S20, (vi) S25 and (vii) $\mathrm{S} 30$ in the $1130-1190 \mathrm{~cm}^{-1}$ spectra region.

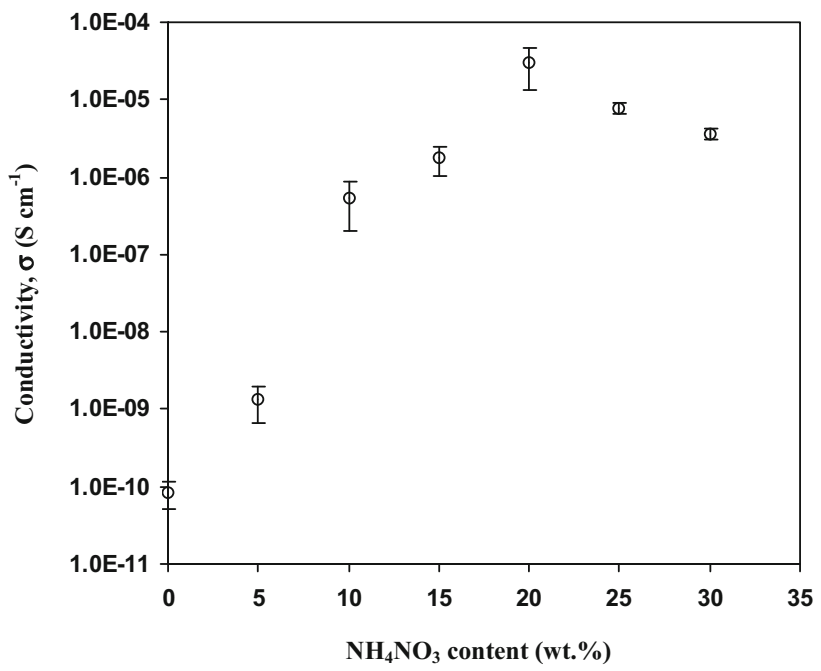

Figure 2. Room temperature conductivity vs. salt content.

the $v_{\text {as }}\left(\mathrm{NH}_{4}^{+}\right)$and $v_{\mathrm{s}}\left(\mathrm{NH}_{4}^{+}\right)$modes can be noticed at 3255 and $3083 \mathrm{~cm}^{-1}$ respectively. According to the authors, the symmetry of $\mathrm{NH}_{4}^{+}$is reduced which in turn reflects interaction between the polymer and $\mathrm{NH}_{4}^{+}$. As can be noticed in figure $2 \mathrm{i}$, the peak at $1154 \mathrm{~cm}^{-1}$ is assigned as a glycosidic 
linkage (C-O-C) in dextran. Azmeera et al [21] stated that dextran's glycosidic linkage peak is located around 1157 $\mathrm{cm}^{-1}$. As $5 \mathrm{wt} \% \mathrm{NH}_{4} \mathrm{NO}_{3}$ is added, the $\mathrm{C}-\mathrm{O}-\mathrm{C}$ peak shifts to $1152 \mathrm{~cm}^{-1}$ and is further moved to a lesser wavenumber as $20 \mathrm{wt} \% \mathrm{NH}_{4} \mathrm{NO}_{3}$ is added. This outcome signifies that $\mathrm{NH}_{4}^{+}$interacted with the oxygen atom of the glycosidic linkage. When the salt concentration exceeds $20 \mathrm{wt} \%$, the peak of $\mathrm{C}-\mathrm{O}-\mathrm{C}$ changes to a higher wavenumber which indicates ion aggregate formation. High ion aggregations lead to the decrement in charge carrier's concentration which reduces the ionic conductivity $[22,23]$.

\subsection{Conductivity analysis at room temperature}

Figure 2 displays the room-temperature conductivity against $\mathrm{NH}_{4} \mathrm{NO}_{3}$ content. Pure dextran film (S0) possesses a conductivity of $(8.24 \pm 3.13) \times 10^{-11} \mathrm{~S} \mathrm{~cm}^{-1}$. The optimum conductivity of $(2.11 \pm 1.43) \times 10^{-5} \mathrm{~S} \mathrm{~cm}^{-1}$ is achieved on addition of $20 \mathrm{wt} \% \mathrm{NH}_{4} \mathrm{NO}_{3}$. On addition of 5-20 wt $\% \mathrm{NH}_{4} \mathrm{NO}_{3}$, the conductivity increases due to charge carrier enhancement and the polymer segment's movement is promoted [24]. Beyond $20 \mathrm{wt} \% \mathrm{NH}_{4} \mathrm{NO}_{3}$, the number of charge carriers decrease and thus lessen the conductivity value. The decline in conductivity is the consequence of ion triplets, ion pairs and ion aggregation development which reduces the number density and mobility of charge carriers [25].

\subsection{Conductivity analysis at various temperatures}

The dependence of temperature on conductivity for S20 electrolyte is shown in figure 3 . The conductivity is elevated with elevating temperature. The linear relation between conductivity and temperature with $R^{2} \sim 0.99$ signifies that the

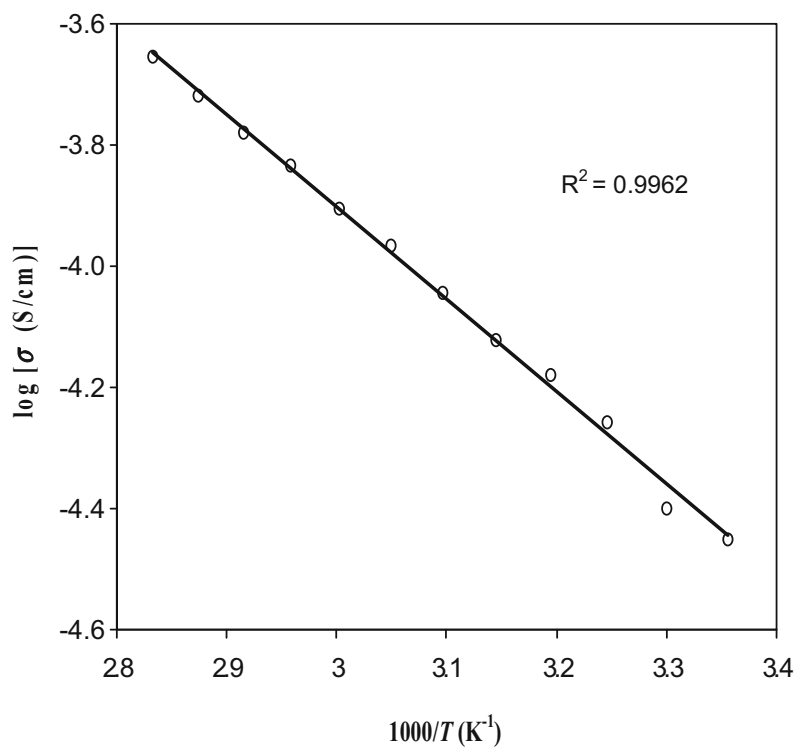

Figure 3. Conductivity for $\mathrm{S} 20$ electrolyte at various temperatures.
S20 electrolyte obeys Arrhenius rule. Arrhenius rule states that the occurrence of ion conduction is due to ion hopping with activation energy, $E_{\mathrm{a}}$ [26]. The equation for Arrhenius theory is given as [27]:

$$
\sigma=\sigma_{0} \exp \left(-E_{\mathrm{a}} / k T\right)
$$

Here, $\sigma_{0}$ stands for factor of pre-exponential, $k$ is the Boltzmann constant and absolute temperature is given as $T$. Other studies on ammonium salt-based electrolyte also reported Arrhenius behaviour such as methylcellulose$\mathrm{NH}_{4} \mathrm{NO}_{3}$ [28], starch- $\mathrm{NH}_{4} \mathrm{NO}_{3}$ [29] and $\mathrm{PVA}-\mathrm{NH}_{4} \mathrm{NO}_{3}$ [30]. The value of $E_{\mathrm{a}}$ for $\mathrm{S} 20$ can be extracted from the slope of the plot in figure 3. It is found that the $E_{\mathrm{a}}$ value is $0.30 \mathrm{eV}$.
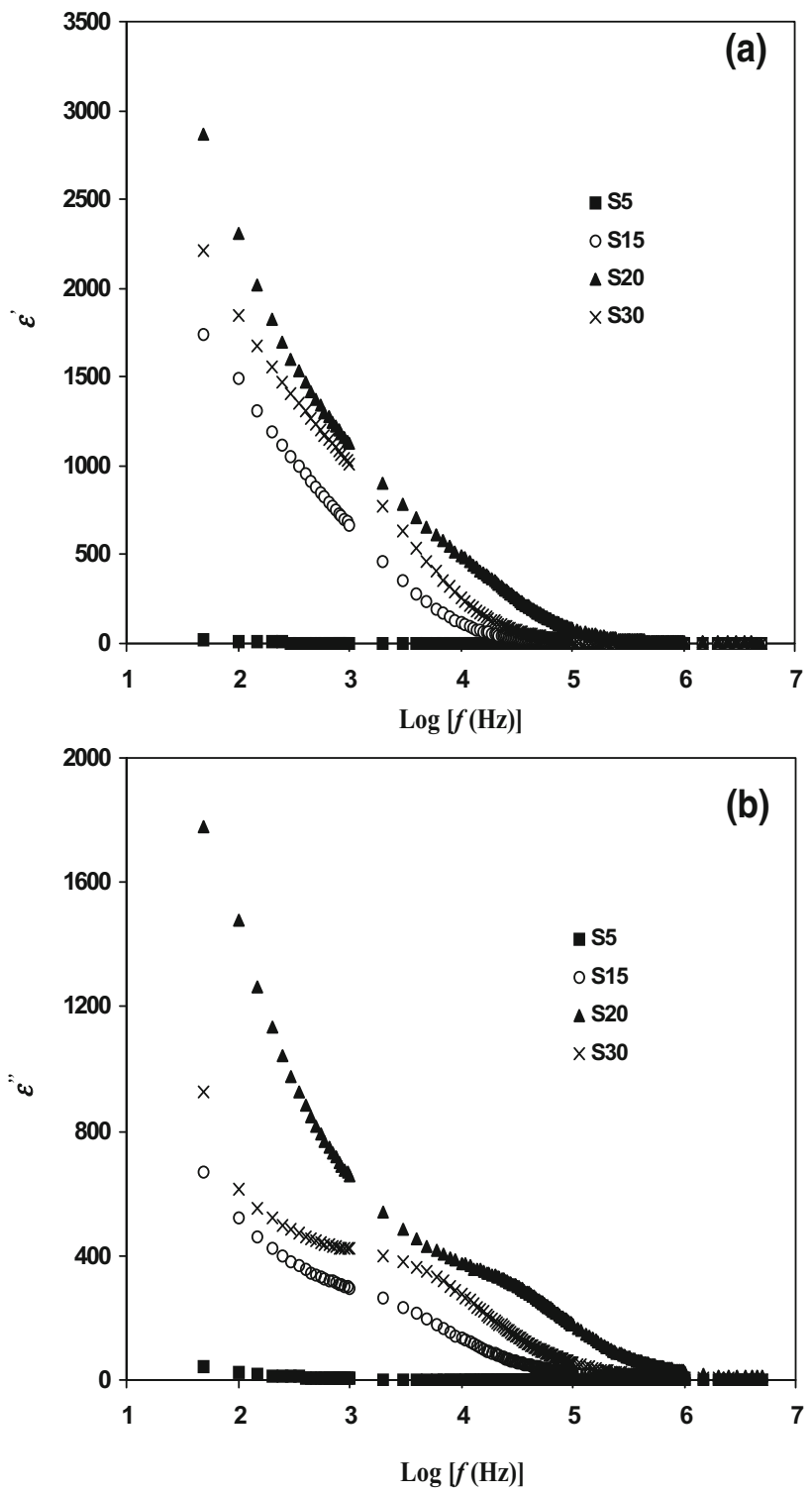

Figure 4. The effect of salt content on (a) $\varepsilon^{\prime}$ and (b) $\varepsilon^{\prime \prime}$ at room temperature and different frequencies. 


\subsection{Dielectric analysis}

The real $\varepsilon^{\prime}$ and imaginary $\varepsilon^{\prime \prime}$ components of the dielectric permittivity $\varepsilon^{*}$, which are known as dielectric constant and dielectric loss respectively, are obtained from [31]:

$$
\begin{aligned}
\varepsilon^{\prime} & =\frac{Z^{\prime \prime}}{\omega C_{0}\left(\left(Z^{\prime}\right)^{2}+\left(Z^{\prime \prime}\right)^{2}\right)} \\
\varepsilon^{\prime \prime} & =\frac{Z^{\prime}}{\omega C_{0}\left(\left(Z^{\prime}\right)^{2}+\left(Z^{\prime \prime}\right)^{2}\right)}
\end{aligned}
$$

Here, $Z^{\prime}$ stands for the real component of impedance, $Z^{\prime \prime}$ represents the imaginary component of impedance, $\omega$ represents the circular frequency and vacuum capacitance is given as $C_{0}$. The variation of $\varepsilon^{\prime}$ and $\varepsilon^{\prime \prime}$ with $\mathrm{NH}_{4} \mathrm{NO}_{3}$ content is shown in
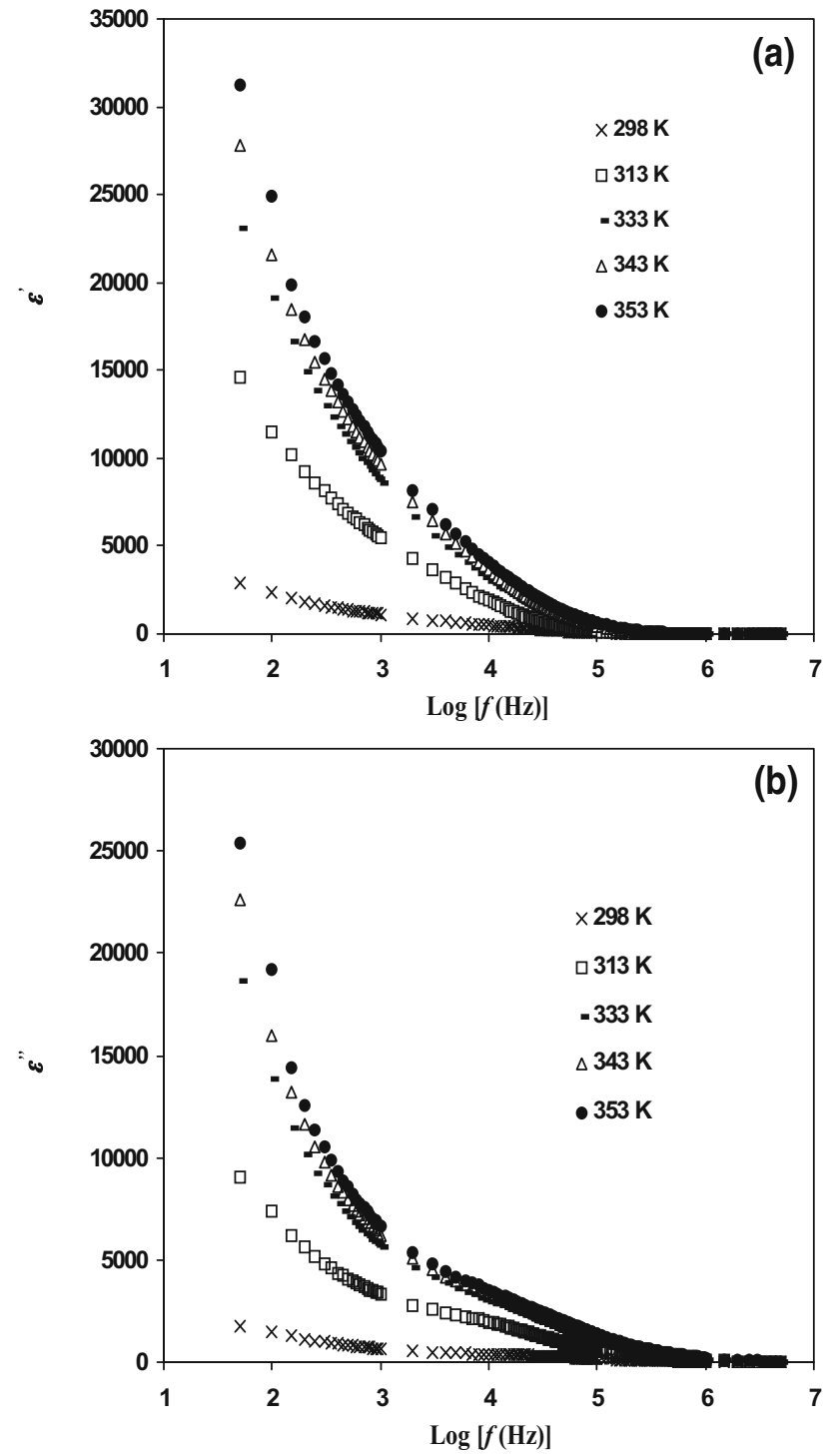

Figure 5. The effect of temperature on (a) $\varepsilon^{\prime}$ and (b) $\varepsilon^{\prime \prime}$ for S20 at different frequencies. figure $4 \mathrm{a}$ and $\mathrm{b}$, respectively. Both $\varepsilon^{\prime}$ and $\varepsilon^{\prime \prime}$ are reduced with the increase in frequency which can be initiated from the rapid polarization of charge carriers due to the presence of the electric field. As a result, ions stay in the bulk of the electrolyte resulting in the decrement in polarization thus reducing $\varepsilon^{\prime}$ and $\varepsilon^{\prime \prime}$ values. This phenomenon can be explained by nonDebye behaviour which will be discussed in loss tangent $(\tan \delta)$ section [32]. It is observed that $\varepsilon^{\prime}$ and $\varepsilon^{\prime \prime}$ increase with the addition of $\mathrm{NH}_{4} \mathrm{NO}_{3}$. Incorporation of salt into the polymer matrix enhances charge carrier localization [33]. This result followed the pattern of conductivity. $\varepsilon^{\prime}$ and $\varepsilon^{\prime \prime}$ values for S20 increase with the elevating temperature as displayed in figure $5 \mathrm{a}$ and $\mathrm{b}$, respectively. The ion dissociation process is enhanced at a high temperature which in turn increases the value of $\varepsilon^{\prime}$ and $\varepsilon^{\prime \prime}$.

\subsection{Loss tangent (tan $\delta)$ analysis}

Figure 6 illustrates loss tangent $(\tan \delta) v s$. log frequencies at $298 \mathrm{~K}$. The $\tan \delta$ and relaxation time $\left(t_{\mathrm{r}}\right)$ can be expressed as:

$$
\begin{aligned}
\tan \delta & =\frac{\varepsilon_{\mathrm{i}}}{\varepsilon_{\mathrm{r}}} \\
t_{\mathrm{r}} & =\frac{1}{\omega_{\max }} .
\end{aligned}
$$

Here, $\omega_{\max }$ stands for relaxation peak's circular frequency. The $\tan \delta$ 's peak shifts to a higher frequency value indicating that the relaxation time is reduced. The $t_{\mathrm{r}}$ was calculated and can be shown in table 2 . S20 possesses the lowest $t_{\mathrm{r}}$ value of $8.38 \times 10^{-7} \mathrm{~s}$. This is due to faster movement of ions that follows the orientation of the electric field [34]. The movement of the peak towards a high-frequency region proposes faster relaxation time as reported by Pradhan et al [35] and this is comparable with the outcome in this study.

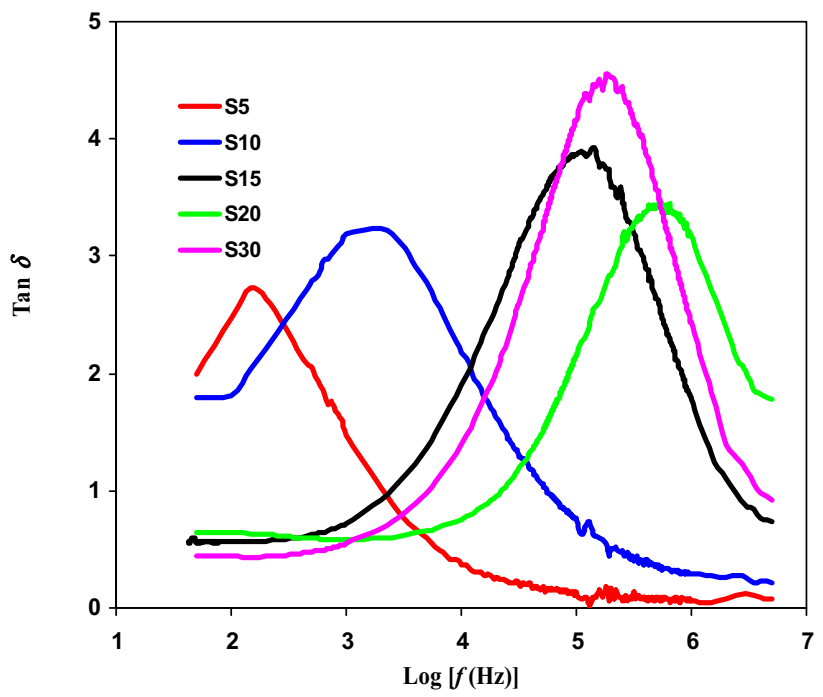

Figure 6. The effect of salt content on $\tan \delta$ at room temperature with different frequencies. 
Table 2. Relaxation time for selected salt electrolytes.

\begin{tabular}{lc}
\hline Electrolyte & $t_{\mathrm{r}}(\mathrm{s})$ \\
\hline S5 & $1.06 \times 10^{-3}$ \\
S10 & $7.96 \times 10^{-5}$ \\
S15 & $1.45 \times 10^{-6}$ \\
S20 & $8.38 \times 10^{-7}$ \\
S30 & $2.70 \times 10^{-7}$ \\
\hline
\end{tabular}
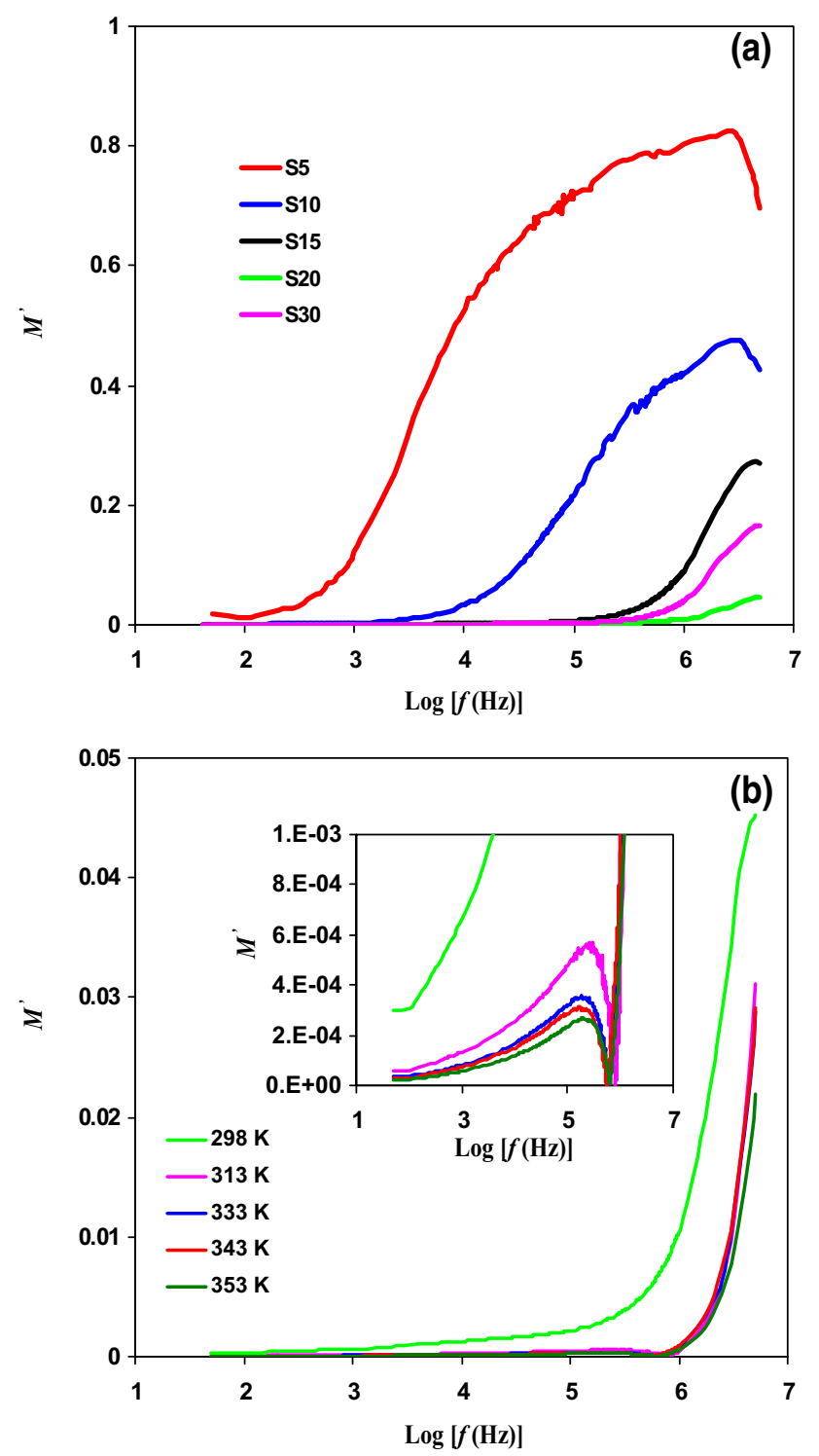

Figure 7. The effect of (a) salt content at room temperature and (b) temperature at various frequencies on $M^{\prime}$.

\subsection{Electrical modulus analysis}

The real part $\left(M^{\prime}\right)$ and imaginary part $\left(M^{\prime \prime}\right)$ of electrical modulus was obtained using the following equations:

$$
\begin{aligned}
M^{\prime} & =\frac{\varepsilon^{\prime}}{\left(\left(\varepsilon^{\prime}\right)^{2}+\left(\varepsilon^{\prime \prime}\right)^{2}\right)} \\
M^{\prime \prime} & =\frac{\varepsilon^{\prime \prime}}{\left(\left(\varepsilon^{\prime}\right)^{2}+\left(\varepsilon^{\prime \prime}\right)^{2}\right)} .
\end{aligned}
$$

The frequency dependence of $M^{\prime}$ at $298 \mathrm{~K}$ is shown in figure $7 \mathrm{a} . M^{\prime}$ value is approaching zero at low frequency region and increases towards higher frequency region. This is attributed to the electrode polarization at low frequency region [36]. This further confirms the non-Debye theory. S20 electrolyte has been employed to analyse the frequency dependence of $M^{\prime}$ at different temperatures from 298 to
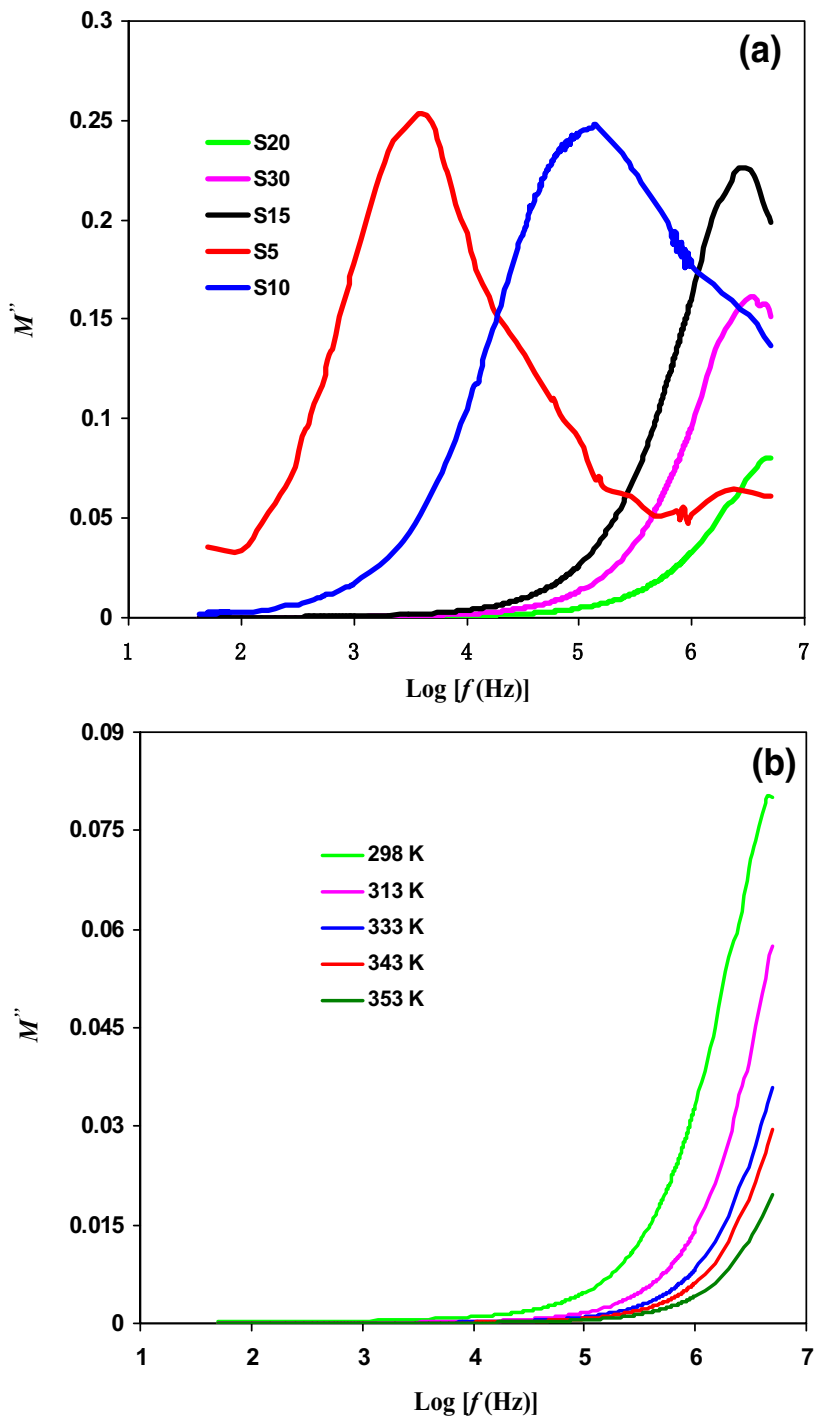

Figure 8. The effect of (a) salt content at room temperature and (b) temperature at various frequencies on $M^{\prime \prime}$. 
$353 \mathrm{~K}$, which can be observed in figure $7 \mathrm{~b}$. As the temperature is increased, the amount of free ions also increase which in turn decreases the value of $M^{\prime}$ [37,38]. The frequency dependence of $M^{\prime \prime}$ at $298 \mathrm{~K}$ is displayed in figure 8a. It can be noticed that higher conducting electrolyte's peak is situated at a higher frequency region. The peaks in $M^{\prime \prime}$ plot indicate that the electrolytes are ionic conductors [39]. Furthermore, the $M^{\prime \prime}$ plot is divided by a maximum peak into two regions which include a low frequency and a high-frequency region. The low and high-frequency regions represent the process of conduction and relaxation, respectively [40]. Figure 8b illustrates $M^{\prime \prime}$ vs. $\log$ frequencies for S20 electrolyte at different temperatures from 298 to $353 \mathrm{~K}$. It can be noticed that $M^{\prime \prime}$ value reduces as the temperature increases. As reported by Aziz et al [41], at a higher temperature, polymer segmental motion and the mobility of free ions are enhanced.

\subsection{FESEM analysis}

Figure 9 displays the surface of the electrolytes. In figure 9a, pure dextran (S0) possesses a homogeneous and smooth surface without any porous structure. This result is comparable
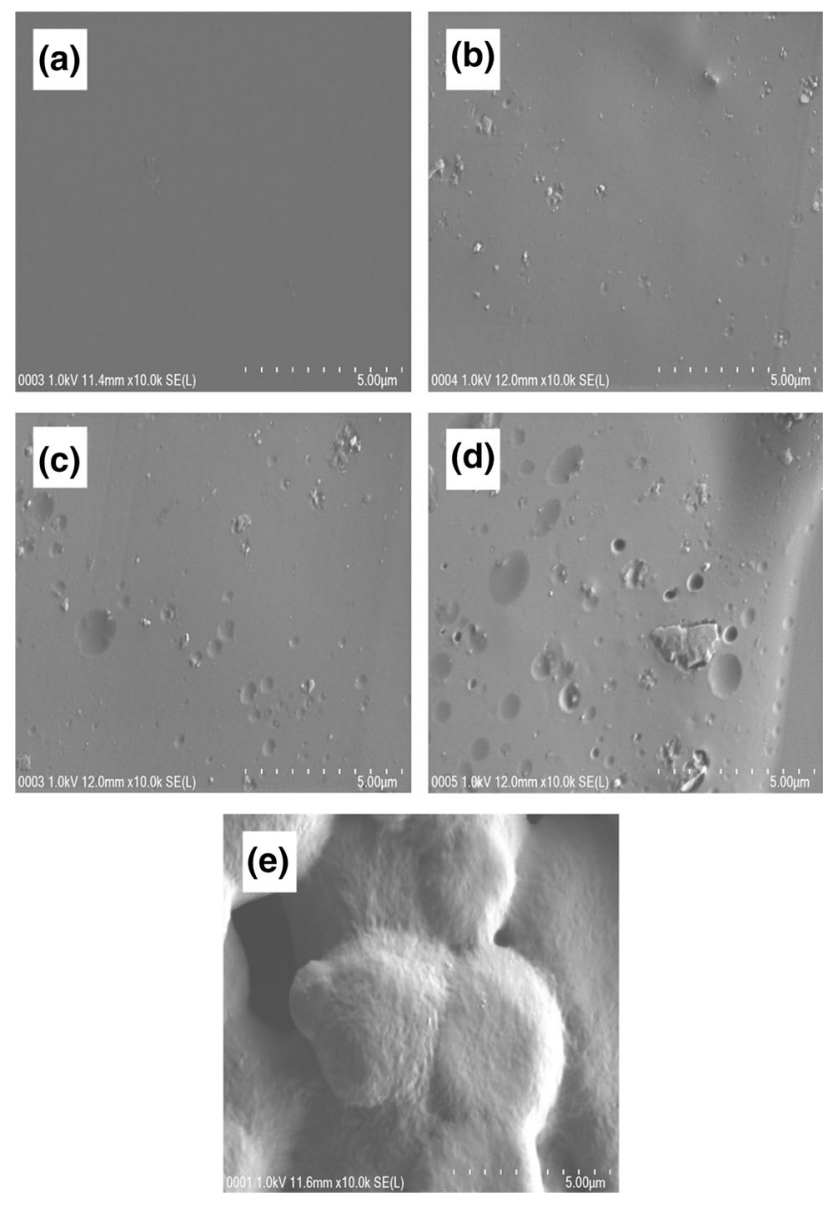

Figure 9. Surface of (a) pure dextran (S0), (b) S10, (c) S20, (d) S25 and (e) S30. with other study [42]. The addition of $10 \mathrm{wt} \% \mathrm{NH}_{4} \mathrm{NO}_{3}$ changes the morphology to a porous structure with several particles on the electrolyte surface. Porous structure assists in diffusivity of free ions and ionic conductivity enhancement [43]. The particles play a role as channels for conduction of ions through the electrolyte [44]. More particles and pores are observed as $20 \mathrm{wt} \%$ of $\mathrm{NH}_{4} \mathrm{NO}_{3}$ is added. By referring to $\mathrm{Xi}$ et al [45], the increase in porosity aids in increment of the conductivity. As observed in figure 9e, as more salt is added, more particles protrude out of the surface. This indicates that the polymer matrix is unable to accommodate excess salt which in turn leads to salt recrystallization. As recrystallization occurs, the amount of free ions decreases which results in decrement of the conductivity $[45,46]$.

\subsection{XRD analysis}

XRD patterns of pure $\mathrm{NH}_{4} \mathrm{NO}_{3}$ and selected electrolytes can be observed in figure 10a and $\mathrm{b}$, respectively. XRD pattern for pure $\mathrm{NH}_{4} \mathrm{NO}_{3}$ in this study is comparable to other study [47]. XRD pattern for pure dextran film (S0) consists of obvious crystalline peaks at around $2 \theta=16.5$ and $22.4^{\circ}$.
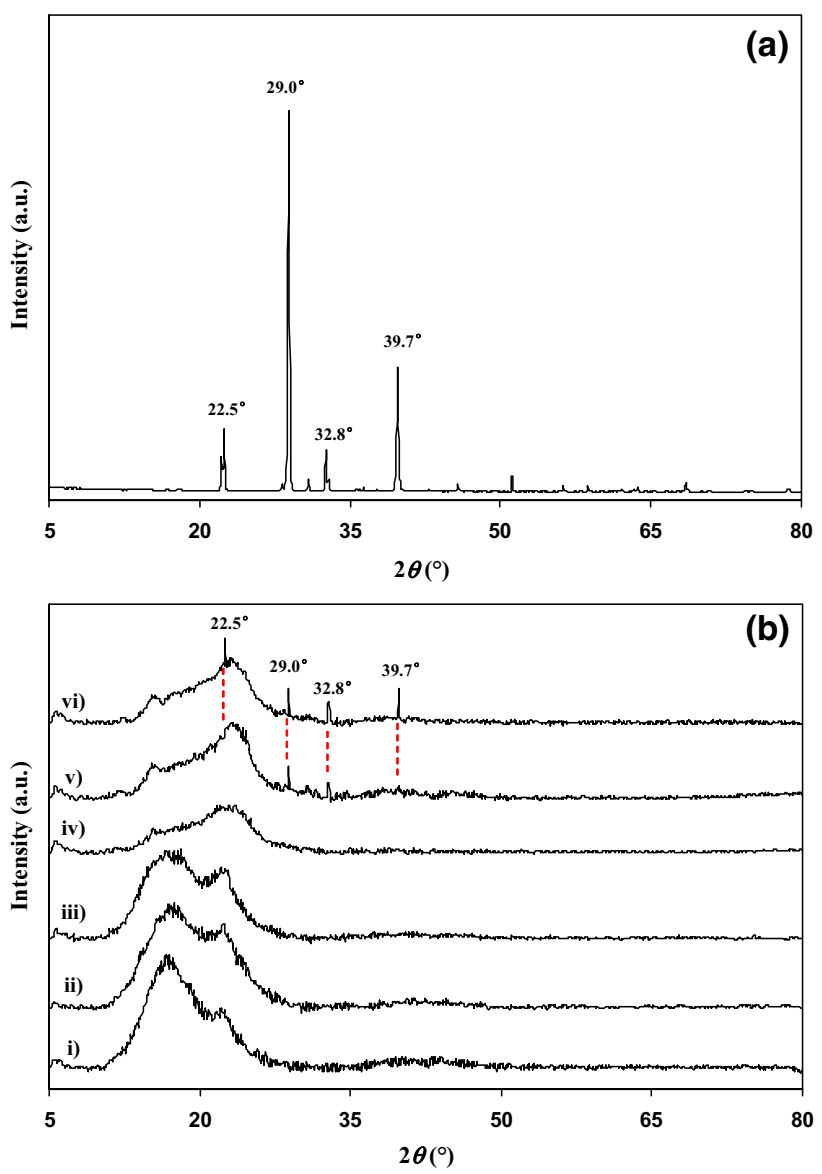

Figure 10. XRD pattern of (a) pure $\mathrm{NH}_{4} \mathrm{NO}_{3}$ and (b) XRD patterns for (i) S0, (ii) S5, (iii) S10, (iv) S20, (v) S25 and (vi) S30. 
This outcome is comparable to other study [48]. These peaks become less intense and sharp as $10 \mathrm{wt} \%$ of $\mathrm{NH}_{4} \mathrm{NO}_{3}$ is added. When $20 \mathrm{wt} \%$ of $\mathrm{NH}_{4} \mathrm{NO}_{3}$ is added, the crystalline peak of pure dextran becomes broader and less intense. In addition, the absence of $\mathrm{NH}_{4} \mathrm{NO}_{3}$ crystalline peaks indicates that the salt is dissolved in the polymer matrix [49]. As the concentration of $\mathrm{NH}_{4} \mathrm{NO}_{3}$ exceeds $20 \mathrm{wt} \%$, sharp crystalline peaks appear at $2 \theta=22.5,29,32.8$ and $39.7^{\circ}$, respectively. These peaks indicate that the salt has been recrystallized [50]. This result is in agreement with FESEM analysis where a solid crystal can be observed as more than 20 wt $\%$ of $\mathrm{NH}_{4} \mathrm{NO}_{3}$ is included. This phenomenon reduces the ionic number density which decreases the conductivity [51].

\section{Conclusion}

The solution cast method has been successfully used to prepare dextran doped with $\mathrm{NH}_{4} \mathrm{NO}_{3}$ films. The interaction among the materials in the film has been confirmed by the shifting of peaks in FTIR outcomes. The conductivity of pure dextran film at room temperature is found to be $(8.24 \pm 0.31) \times 10^{-11} \mathrm{~S} \mathrm{~cm}^{-1}$ and the inclusion of $20 \mathrm{wt} \%$ has improved the conductivity up to $\sim 10^{-5} \mathrm{~S} \mathrm{~cm}^{-1}$. The pattern of conductivity is strengthened by the outcomes of dielectric study and the electrolytes followed non-Debye behaviour. The addition of $\mathrm{NH}_{4} \mathrm{NO}_{3}$ into the pure dextran film has transformed the surface of the electrolytes to porous structure. The results from FESEM and conductivity studies are strengthened by XRD analysis.

\section{Acknowledgements}

The authors thank the University of Malaya for the Grants FP009-2015A, RP010B-13AFR and BKS005-2018 awarded.

\section{References}

[1] Chai M N and Isa M I N 2016 Sci. Rep. 61

[2] Shukur M F, Ithnin R and Kadir M F Z 2014 Ionics 7977

[3] Nur U T and Nurul H I 2014 J. Membr. Sci. 468149

[4] Ramlli M A and Isa M I N 2016 J. Phys. Chem. B 12011567

[5] Zhu Y S, Xiao S Y, Li M X, Chang Z, Wang F X, Gao J et al 2015 J. Power Sources 288368

[6] Shanti N, Azlin S, Ahmada A H, Ramesh S, Ramesh K and Othmana N 2015 J. Teknologi 751

[7] Abu Bakar N Y, Muhamaruesa N H, Bashirah Aniskari N A and Mohd Isa M I N 2015 Am. J. Appl. Sci. 1240

[8] Mohammad H K, Ramesh S and Ramesh K 2015 Sci. Rep. 51

[9] Song A, Huang Y, Zhong X, Cao H, Liu B, Lin Y et al 2017 Electrochim. Acta 245981

[10] Gong S-D, Huang Y, Cao H-J, Lin Y-H, Li Y, Tang S-H et al 2016 J. Power Sources 307624

[11] Hamsan M H, Shukur M F and Kadir MFZ2017 Ionics 231137
[12] Maria D, Madalina A, Marian V, Catalin V and Viorica M 2012 Solid State Phenom. 188102

[13] Telegeev G, Kutsevol N, Chumachenko V, Naumenko A, Telegeeva P, Filipchenko S et al 2017 Int. J. Polym. Sci. 20171

[14] Osman Z, Mohd Ghazali M I, Othman L and Md Isa K B 2012 Results in Phys. 21

[15] Sudhakar Y N and Selvakumar M 2012 Electrochim. Acta 78398

[16] Kang J, Li W, Wang X, Lin Y, Li X, Xiao X et al 2004 J. Appl. Electrochem. 34301

[17] Sikkanthar S, Karthikeyann S, Selvasekarapandian S, Pandi D V, Nithya S et al 2014 J. Solid State Electrochem. 4987

[18] Mohanasrinivasan V, Ghosa T, Thaslim J B, Zeba H J, Selvarajan E, Suganthi V et al 2014 Res. J. Pharm. Tech. 78

[19] Shukur MF 2015 PhD Thesis (Malaysia, University of Malaya)

[20] Kadir M F Z, Aspanut Z, Majid S R and Arof A K 2011 Spectrochim. Acta Part A $\mathbf{7 8} 1068$

[21] Azmeera V, Adhikary P and Krishnamoorthi S 2012 Int. J. Carbohydr. Chem. 20121

[22] Hafiza M N and Isa M I N 2017 Carbohydr. Polym. 165 123

[23] Monisha S, Mathavan T, Selvasekarapandian S, Benial A, Aristatil G, Mani N et al 2017 Carbohydr. Polym. 15738

[24] Kadir M F Z, Salleh N S, Hamsan M H, Aspanut N A and Shukur M F 2018 Ionics 241651

[25] Misenan M S M, Isa M I N and Khiar A S A 2018 Mater. Res. Express 20531

[26] Hamsan M H, Shukur M F and Kadir M F Z 2017 Ionics 23 3429

[27] Rasali N M J and Samsudin A S 2018 Ionics 241639

[28] Shuhaimi N E A, Majid S R and Arof A K 2009 Mater. Res. Innovations $\mathbf{1 3} 239$

[29] Khiar A S and Arof A K 2010 Ionics 16123

[30] Selvasekarapandian S, Hema M, Kawamura J, Kamishima O and Baskaran R 2010 J. Phys. Soc. Jpn. 79163

[31] Shahenoor Basha S K, Sunita Sundari G, Vijay Kumar K and Rao M C 2017 J. Inorg. Organomet. Polym. 27455

[32] Das S and Ghosh A 2015 AIP Adv. 51

[33] Chandra A 2013 Indian J. Pure Appl. Phys. 51788

[34] Deraman S K, Subban R H Y and Mohamed N S 2017 J. Appl. Environ. Biol. Sci. 7152

[35] Pradhan D K, Choudhary R N P and Samantaray B K 2009 Mater. Chem. Phys. 115557

[36] Gurusiddappa J, Madhuri W, Suvarna R P and Dasan K P 2016 Indian J. Adv. Chem. Sci. 414

[37] Ramesh S and Arof A K 2001 Mater. Sci. Eng. B 8511

[38] Wang W and Alexandridis P 2016 Polymer 8387

[39] Rozali M L H and Isa M I N 2014 Int. J. Mater. Sci. 459

[40] Kobayashi T, Noguchi Y and Miyayama M 2005 Appl. Phys. Lett. 8601290

[41] Aziz S B, Abidin Z H Z and Arof A K 2010 XPRESS Polym. Lett. 4300

[42] Cascone M G, Polacco G, Lazzeri L and Barbani N $1997 \mathrm{~J}$. Appl. Polym. Sci. 662089

[43] Ahmad A L, Farooqui U R and Hamid N A 2018 Electrochim. Acta 283842

[44] Bhad S N and Sangawar V S 2013 Int. J. Sci. Eng. Res. 41719

[45] Xi J, Qiu X, Li J, Tang X, Zhu W and Chen L 2006 J. Power Sources 157501

[46] Yusof Y M, Shukur M F, Illias H A and Kadir M F Z 2014 Phys. Scr. 89035701 
[47] Kento S, Hiroki M and Atsumi M 2017 J. Therm. Anal. Calorim. 127851

[48] Kadir M F Z and Hamsan M H 2018 Ionics 242379

[49] Noor S A M, Ahmad A, Rahman M Y A and Talib I A 2010 Nat. Sci. 2190
[50] Amran N N A, Manan N S A and Kadir M F Z 2016 Ionics 221647

[51] Danielle M, Yukyung J, Alexandra L H, Michael A W, Geoffrey W C and Nitash B 2016 Solid State Ion. 289 118 